Margarita Gutiérrez-Moret, Remedios Aguilar-Moya, Raquel Ibáñez-Martínez, Antonio Vidal-Infer

Spain

\title{
Ability vs. Self-Perception in Emotional Intelligence: Do We Measure the Same Thing?
}

DOI: $10.15804 /$ tner.2017.48.2.20

\begin{abstract}
TMMS and MSCEIT are the most frequently used tools to assess emotional intelligence. TMMS is a questionnaire to self-evaluate emotional skills, and MSCEIT is a test to measure emotional intelligence. Given that both are used equally, we examined the relationship between their dimensions. A sample of 252 adults was selected from higher education institutions. MSCEIT and TMMS-24 were administered and ANOVA and Pearson correlation analyses were conducted. The MSCEIT Managing Emotions branch was the only area that discriminates among participants. A new combined tool to assess EI is proposed in this study.
\end{abstract}

Keywords: emotional intelligence, ability, self-perception, MSCEIT, TMMS

\section{Introduction}

The importance of emotions in the field of education and the development of new learning methodologies have contributed to the current increase in studies aimed at measuring emotional intelligence and its relationship with the new education.

Emotional intelligence (EI) refers to the ability to perceive and identify emotions in oneself and others, the ability to regulate and modify one's state of mind in an appropriate manner, and the ability to improve reasoning (Mayer \& Salovey, 1997). This model also proposes the concept of Perceived Emotional Intelligence 
(PEI), which refers to "one's beliefs about the level of control, clarity, acceptance, authenticity and variability of one's current emotional state. It focuses on the cognitive processes that accompany an ongoing emotional experience (meta-emotional experience)" (Mayer \& Gaschke, 1988).

Different methods and instruments are used to assess PEI, such as the TraitMeta-Mood Scale or TMMS-48 (Salovey, Mayer, Goldman, Turvey \& Palfai, 1995), which have been used equally as ability measures like the MSCEIT (Mayer, Salovey \& Caruso, 2002; Brakett \& Salovey, 2006; Extremera, Fernández-Berrocal, \&Salovey, 2006.). TMMS-48 is the most frequently used tool to assess beliefs related to emotional attention (attention to our own emotional states), emotional clarity (understanding of our emotional states) and emotional repair (ability to repair our negative emotional states).

Theorists now recognize the ability model as the most authoritative approach to EI (Matthews, Roberts \& Zeidner, 2004; Rivers, Brackett, Salovey, \& Mayer, 2007; Extremera\&Berrocal, 2004), but it takes also more time and money to conduct ability tests. Self-perception tools, such as TMMS-48, are cheaper and shorter, and there is no need for the presence of a psychologist to collect data. Several studies on EI based on the Salovey and Mayer model have used these self-perception instruments to evaluate EI, assuming that results refer to EI, but they do not highlight that it is about PEI.

A study by Wilson \& Dunn (2004) revealed that EI measures based on self-perception do no correlate with real situations in the same way as ability measures do. These results might indicate that measures of perceived competences and ability measure different emotional perspectives (Warwick \& Nettelbeck, 2004).

This study aims at comparing TMMS and MSCEIT scores in order to establish or discard a correspondence among their specific scales.

\section{Methodology}

\section{Participants}

Data were retrieved from a sample of 252 students, $71.4 \%$ male, with a mean age of 27.4, from different studies in higher education.

\section{Materials}

Two of the main instruments were selected to assess PEI and EI: a self-report questionnaire (TMMS-24) and a skills performance test (MSCEIT), both based on Mayer \& Salovey's (1997) EI model. 
The TMMS-24 Trait Meta Mood Scale-24 (Fernández-Berrocal, Extremera \& Ramos, 2004) is an adaptation of the TMMS-48 developed by Mayer \& Salovey in 1990. The scale is made up of 24 items grouped in 3 dimensions: attention to feelings, understood as the degree to which people believe they pay attention to their emotions and feelings; emotional clarity or how people think they perceive their emotions; and repair of emotions, defined as the belief of the subject in his or her ability to stop and adjust negative emotional states and prolong positive ones (Fernández-Berroca 1\& Extremera, 2008). The test was corrected through the evaluation of the direct scores by means of the measuring scales shown in table 1.

Table 1. Measuring scales on the TMMS-24

\begin{tabular}{llll}
\hline & & \multicolumn{1}{c}{ Men } & Women \\
\hline Attention to feelings & Poor & $<21$ & $<24$ \\
\cline { 2 - 4 } & Adequate & 22 to 32 & 25 to 35 \\
\cline { 2 - 4 } & Excessive & $<33$ & $<36$ \\
\hline Emotional clarity & Poor & $<25$ & $<23$ \\
\cline { 2 - 4 } & Adequate & 26 to 35 & 24 to 34 \\
\cline { 2 - 4 } & Excellent & $>36$ & $>35$ \\
\hline Repair of emotions & Poor & $<23$ & $<23$ \\
\cline { 2 - 4 } & Adequate & 24 to 35 & 24 to 34 \\
\cline { 2 - 4 } & Excellent & $>36$ & $>35$ \\
\hline
\end{tabular}

Source: Fernández-Berrocal, Extremera\& Ramos, 2004.

The MSCEIT (Mayer, Salovey, \& Caruso, 2002) Emotional Intelligence Test was used in its Spanish adaptation (Extremera \& Fernández-Berrocal, 2002). The MSCEIT is an instrument based on task skills made up of 141 items that measure how well people perform tasks and solve emotional problems in eight scenarios. Scores are divided into two areas (experiential EI and strategic EI) and four branches (perception, use, understanding and emotional management).

\section{Procedure}

The participants took the test in a one-hour session in the same classroom where teaching took place. Self-administration of the instruments was supervised by a psychologist and three pedagogues and followed this order: brief demographic questionnaire, TMMS-24 and MSCEIT. All along the study, the participants were informed of the purpose of the study and the voluntary nature of participation in it, whilst also ensuring anonymity and confidentiality of the data. 


\section{Data analysis}

The data were recorded and analysed with the use of the statistical software package SPSS 22.0. A one-factor analysis of variance was conducted to observe differences in scores according to the used instrument. Finally, the Bonferroni test for post hoc contrasts was used.

\section{Results}

The MSCEIT General Emotional Intelligence is completely independent of the TMMS-24 self-perception. Thus, there are not significant differences among the groups in any of the 3 TMMS-24 areas. Differences were found in the MSCEIT Managing Emotions branch (table 2)

Table 2. One-factor ANOVA (TMMS-24 scales)

\begin{tabular}{lllllll}
\hline & \multicolumn{2}{c}{$\begin{array}{c}\text { Factor TMMS } \\
\text { Emotional } \\
\text { Attention }\end{array}$} & $\begin{array}{c}\text { Factor TMMS } \\
\text { Emotional } \\
\text { Clarity }\end{array}$ & $\begin{array}{c}\text { Factor TMMS } \\
\text { Emotional } \\
\text { Repair }\end{array}$ \\
\hline & F & Sig & F & Sig & F & Sig \\
\hline MSCEIT General EI & 1.185 & 0.308 & 0.300 & 0.741 & 0.335 & 0.716 \\
\hline MSCEIT Experiential EI area & 0.162 & 0.850 & 0.454 & 0.636 & 1.930 & 0.147 \\
\hline MSCEIT Strategic EI area & 1.644 & 0.195 & 1.820 & 0.164 & 2.368 & 0.096 \\
\hline MSCEIT Perceiving Emotions branch & 0.172 & 0.842 & 1.072 & 0.344 & 0.944 & 0.390 \\
\hline MSCEIT Facilitating Thoughts branch & 0.466 & 0.628 & 0.038 & 0.963 & 1.829 & 0.163 \\
\hline MSCEIT Understanding Emotions branch & 1.016 & 0.364 & 0.183 & 0.833 & 0.601 & 0.549 \\
\hline MSCEIT Managing Emotions branch & 1.479 & 0.230 & 6.326 & 0.002 & 3.818 & 0.023 \\
\hline
\end{tabular}

The Bonferroni post hoc tests showed that significant differences were found uniquely in the MSCEIT Managing Emotions branch when comparing the groups of TMMS Emotional Clarity 'Poor' and 'Adequate' $(\mathrm{p}=0.023)$ and 'Poor' and 'Excellent' $(\mathrm{p}=0.003)$, and the groups of TMMS Emotional Repair 'Poor' and 'Excellent' $(\mathrm{p}=0.019)$.

\section{Discussion}

Scientific literature has approached the study of EI from the perspectives of ability and self-perception. As evidenced from the results of the presented study, the scores of the TMMS-24 and the MSCEIT are independent from each other 
except for the branch of emotional handling of the MSCEIT. This corroborates the initial hypothesis of the presented study, where it was considered that they are complementary instruments, but in no case can the measurement of the self-report replace the ability scores.

The study of the general measures of EI in the MSCEIT, general emotional intelligence and the strategic and experiential areas, does not have any relation with the three areas of the TMMS-24. This is congruous with other studies where differences are not so clear in the general levels of EI, although there are in some of its sub-dimensions (Bar-On, 2006). It is, therefore, necessary to carry out a detailed analysis of the scores on the MSCEIT, by specific branches, to discover possible overlapping between both instruments. In the presented study, this overlapping is between the branch of emotional handling of the MSCEIT and the branches of the TMMS-24 of clarity and emotional repair. There is a possible explanation for this connection between the subscales; effective emotional handling generates positive mood states in oneself and others so it can offer clearer information to people on their own emotional management abilities. This way, high performance on execution tests using emotions to make adequate decisions has an effect on a better ability to understand and regulate emotional states.

On the other hand, it must be mentioned that the levels of execution in perception, facilitation and emotional understanding do not show a direct relation with the perception that the subject has of their emotional skills. For instance, in the case of understanding, it has specific subscales in both instruments; nevertheless, a relation between both subscales has not been seen, since they are differentiated constructs. The branch of understanding of the MSCEIT evaluates the real understanding that the individual has of emotions, and the branch of understanding of the TMMS-24 (clarity) is a measurement of the perception that the individual has on his/her understanding of the emotions. That is, we are dealing with two different approaches of understanding, where none of them must be obviated. Therefore, special caution is recommended when speaking of self-report measures and extrapolating the results to the study of EI as an ability.

As a final summary, the TMMS-24 and the MSCEIT must be complementary instruments in the study of emotional intelligence. Both instruments separately have limitations (Maul, 2012; Richard et al., 2006), therefore it is highly advisable to use both to take advantage of their strengths and to diminish their disadvantages.

Thus, it is necessary for researchers in emotional education to assess emotional intelligence through self-report and ability measures to obtain a more complete evaluation of EI. 


\section{References}

Brackett, M.A. \&Salovey, P. (2006).Measuring emotional intelligence with the Mayer-Salovery-Caruso Emotional Intelligence Test (MSCEIT). Psicothema, suplem.1, pp. 34-41.

Bar-On, R. (2006). The Bar-On model of emotional-social intelligence (ESI). Psicothema, 18 , suplem.1, pp.13-25.

Extremera, N. \& Fernández-Berrocal, P. (2002). Cuestionario MSCEIT (versión española 2.0) de Mayer, Salovey\&Caruso. Toronto: Multi-Health Systems Publishers.

Extremera, N. \&Fernández-Berrocal, P. (2004). El uso de las medidas de habilidad en el ámbito de la inteligencia emocional: Ventajas e inconvenientes con respecto a las medidas de auto-informe. Boletín de Psicología, 80,pp.59-77.

Extremera, N., Fernández-Berrocal, P., \&Salovey, P. (2006). Spanish version of the Mayer-Salovey-Caruso Emotional Intelligence Test (MSCEIT).Version 2.0: reliabilities, age and gender differences. Psicothema, 18, supl., pp.42-48.

Fernández-Berrocal, P., Extremera, N. \& Ramos, N. (2004). Validity and reliability of the Spanish modified version of the Trait Meta-Mood Scale. Psychological Reports,94, pp. 751-755.doi:https://doi.org/10.2466/pr0.94.3.751-755

Fernández-Berrocal, P. \& Extremera, N. (2008).A review of trait meta-mood research. In A.M. Columbus (eds.), International Journal of Psychology Research, 2, pp. 17-55. New York, NY: Nova Science Publishers.

Matthews, G., Roberts, R.D., \& Zeidner, M. (2004). Seven myths about emotional intelligence. Psychological Inquiry, 15, pp.179-196.

Maul, A. (2012). Examining the structure of emotional intelligence at the item level: New perspectives, new conclusions. Cognition and emotion, 26 (3), pp.503-520.doi: http:// dx.doi.org/10.1080/02699931.2011.588690

Mayer, J.D.\&Gaschke, Y.N. (1988). The experience and meta-experience of mood. Journal of Personality and Social Psychology, 55,pp.102-111. doi: http://dx.doi.org/10.1037/00 22-3514.55.1.102

Mayer, J.D. \&Salovey, P. (1997). What is emotional intelligence?. In P. Salovey \& D. Sluyter (eds.), Emotional development and emotional intelligence: educational applications, (pp. 3-31). New York, NY: Basic Books.

Mayer, J.D., Salovey, P., \& Caruso, D. (2002). Mayer-Salovey-Caruso Emotional Intelligence Test (MSCEIT), Version 2.0. Toronto: Multi-Health Systems.

Richard, R., Schulze, R., O’Brien, K., MacCann, C., Reid, J. \& Maul, A. (2006). Exploring the validity of the Mayer-Salovey-Caruso Emotional Intelligence Test (MSCEIT) with established emotions measures. Emotion, 6 (4), pp. 663-669. doi:http://dx.doi. org/10.1037/1528-3542.6.4.663

Rivers, S.E., Brackett, M.A., Salovey, P. \& Mayer, J.D. (2007). Measuring emotional intelligence as a set of mental abilities. In G. Matthews, M. Zeidner, \& R.D. Roberts (eds.), The science of emotional intelligence (pp. 230-257).New York, NY: Oxford University Press.

Salovey, P., Mayer, J.D., Goldman, S.L., Turvey, C. \& Palfai, T.P. (1995). Emotional attention, clarity, and repair: exploring emotional intelligence using the Trait Meta-Mood Scale. 
In J.W. Pennebaker (eds.), Emotion, Disclosure, \& Health (pp. 125-151). Washington: American Psychological Association.doi: http://dx.doi.org/10.1037/10182-006

Warwick, J., \& Nettelbeck, T. (2004). Emotional intelligence is. . ?.Personality and Individual Differences, 37, pp.1091-1100. doi:http://dx.doi.org/10.1016/j.paid.2003.12.003 Wilson, T. \& Dunn, E. (2004). Self-Knowledge: Its Limits, Value, and Potential for Improvement. Annual Review of Psychology, 55, pp. 493-518. doi:10.1146/annurev. psych.55.090902.141954 